\title{
Aspectos clínicos e características do leite em ovelhas com mastite induzida experimentalmente com Staphylococcus aureus ${ }^{1}$
}

\author{
Rogério A. Santos ${ }^{2}$, Carla L. Mendonça ${ }^{3 *}$, José Augusto B. Afonso ${ }^{3}$ e \\ Luis Carlos V. Simão
}

\begin{abstract}
Santos R.A., Afonso J.A.B., Mendonça C.L. \& Simão, L.C.V. 2007. [Clinical aspects and characteristics of the milk in sheep with mastitis experimentally induced with Staphylococcus aureus.] Aspectos clínicos e características do leite em ovelhas com mastite induzida experimentalmente com Staphylococcus aureus. Pesquisa Veterinária Brasileira 27(1):6-12. Clinica de Bovinos, Universidade Federal Rural de Pernambuco, Campus Garanhuns, Cx.Postal 152, Garanhuns, PE 55292-901, Brazil. E-mail: carlaze@uol.com.br

The objective was to study the clinical aspects and the physical-chemical characteristics of the milk in sheep with mastitis experimentally induced with Staphylococcus aureus. For such, were used 10 Santa Inês primiparity ewes, weighing $30 \mathrm{~kg}$, clinically healthy and housed in a stall. After establishing the normality patterns for the studied variables, the animals were inoculated into one teat of the udder with an inoculum of $1.0 \times 10^{4} \mathrm{ufc} / \mathrm{ml}$ of $S$. aureus, while the other gland served as control. The clinical observations were accomplished in intervals of 12 , $24,36,48,60,72,84,96,108,120,132,168,180,288$ and 336 hours after the inoculation of the agent (PI). All the animals presented clinical systemic manifestations, and in the inoculated glands with more intensity from 24 hours on after the inoculation. There were significant alterations $(\mathrm{P}<0.05)$ in the production and physical-chemical composition of the milk in relation to the controls, with reduction of volume and fat. The $\mathrm{pH}$, the chlorates and CCS reached very high indexes, accompanied by the CMT test reaction. The bacteriological exam revealed the presence of $S$. aureus during the phase of infection. After the treatment of the sheep 36 hours PI, one animal came to death $48 \mathrm{~h}$ PI, and the others showed clinical recovery; however there was no physiologic re-establishment of the inoculated udders which lost their function.
\end{abstract}

INDEX TERMS: Mastitis in sheep, Staphylococcus aureus, milk, somatic cell count.

RESUMO.- Este trabalho teve por objetivo estudar os aspectos clínicos e as características físico-químicas do leite em ovelhas com mastite induzida experimentalmente com Staphylococcus aureus. Foram utilizados dez animais da raça Santa Inês, com

\footnotetext{
${ }^{1}$ Recebido em 25 de abril de 2006

Aceito para publicação em 18 de julho de 2006.

Parte da Dissertação do primeiro autor, apresentada ao Programa de Pós-Graduação em Ciência Veterinária da Universidade Federal Rural de Pernambuco.

${ }^{2}$ Escola Agrícola de Jundiaí, Universidade Federal do Rio Grande do Norte, Av. Jundiaí s/n. Macaíba, RN 59280-000. E-mail: rogerio@eaj.ufrn.br

${ }^{3}$ Clínica de Bovinos, Universidade Federal Rural de Pernambuco, Campus Garanhuns, Av. Bom Pastor s/n, Cx. Postal 152, Garanhuns, PE.55 292-901. *Autor para correspondência: carlaze@uol.com.br

${ }^{4}$ Programa de Pós-Graduação em Ciência Veterinária, Universidade Federal Rural de Pernambuco, Av. Bom Pastor s/n, Cx. Postal 152, Garanhuns, PE.55 292-901.
}

peso médio de $30 \mathrm{~kg}$, fêmeas, primíparas recém-paridas, mantidos em apriscos e clinicamente sadios. Após se estabelecer os padrões de normalidade para as variáveis estudadas, os animais foram inoculados experimentalmente numa mama com uma cepa de $S$. aureus, empregando-se o inóculo de $1,0 \times 10^{4} \mathrm{ufc} /$ $\mathrm{ml}$, enquanto a outra serviu como controle. As observações clínicas e laboratoriais foram realizadas nos intervalos de 12 , $24,36,48,60,72,84,96,108,120,132,168,180,288$ е 336 horas após a inoculação do agente etiológico (PI). Todos os animais apresentaram manifestações clínicas sistêmicas e nas glândulas inoculadas, observadas com mais intensidade a partir de 24 horas após a inoculação. Alterações significativas $(\mathrm{P}<0,05)$ na produção e nos componentes físico-químicos do leite em relação aos seus controles ocorreram, reduzindo o volume e gordura. $\mathrm{O} \mathrm{pH}$, o teor de cloretos e a CCS atingiram índices muito elevados $(\mathrm{P}<0,05)$, acompanhados da reação na prova do CMT. O exame bacteriológico revelou a presença do 
S. aureus durante a fase de infecção. Após a instituição do tratamento nas ovelhas às $36 \mathrm{~h} \mathrm{PI}$, um animal morreu $48 \mathrm{~h} \mathrm{PI}$; nas demais ocorreu a recuperação clínica, no entanto não houve o restabelecimento fisiológico das mamas inoculadas, que perderam a sua funcionalidade.

TERMOS DE INDEXAÇÃO: Mastite em ovelhas, Staphylococcus aureus, leite, contagem de células somáticas.

\section{INTRODUÇÃO}

Na ovinocultura alguns fatores relacionados à sanidade são considerados como limitantes na sua exploração,. Dentre eles se destaca a mastite ovina, que vem se tornando um entrave na criação de ovelhas, devido aos prejuízos econômicos que a mesma acarreta e a limitação na produção de borregos, decorrente do comprometimento funcional da glândula mamária. Alguns trabalhos atribuem como causa primária da mortalidade de borregos a produção insuficiente de leite nas ovelhas devido à mastite clínica e subclínica (Watson \& Buswell 1984, Costa et al. 2001, Mendonça et al. 2005).

A ocorrência de mastite em rebanhos, além de alterações quantitativas e qualitativas do leite, determina perdas econômicas acentuadas principalmente quando há o surgimento de casos clínicos, devido a gastos com assistência veterinária, medicamentos e substituição de matrizes decorrentes da redução da sua vida útil, justificada pela perda das mamas comprometidas e conseqüiente desvalorização comercial dos animais (Kirk \& Glenn 1996, Burriel 1997, Winter 2001).

No Brasil são poucas as informações referentes à mastite em ovelhas. Willians (1966) incluiu a mastite como uma das causas de morte em cordeiros no Rio Grande do Sul. O primeiro relato da doença na espécie ovina foi feito por Fernandes \& Cardoso (1985) ao descreverem um surto de mastite por S. aureus no Rio Grande do Sul. Vaz (1996) em um levantamento realizado em algumas regiões do RS e SC detectou mastite crônica e subclínica causada por diversos agentes, incluindo Staphylococcus aureus. No Nordeste brasileiro, no Estado de Pernambuco, Costa et al. (2001) relataram a ocorrência da doença $(4,19 \%)$, sob a forma clínica em ovelhas.

Entre os agentes etiológicos mais freqüientemente associados à infecção da glândula mamária de ovelhas $S$. aureus e Mannheimia (Pasteurella) haemolytica são responsáveis, isoladamente ou em associação, por $80 \%$ dos casos de mastite clínica aguda (El-Massanat et al. 1991, Scott \& Jones 1998, Winter 2001). Na forma subclínica da doença, além destes agentes envolvidos há a participação de espécies do gênero Staphylococcus coagulase-negativo e Streptococcus sp. (Watkins et al. 1991, Albenzio et al. 2002, Batavani et al. 2003).

As alterações provocadas no tecido mamário pela mastite em ovelhas refletem não somente na produção de leite, mas também no conteúdo celular e nas características físico-químicas, comprometendo a qualidade nutricional deste para a alimentação dos borregos. As células somáticas sofrem elevações em suas contagens quando ocorrem os casos de mastite, na forma clínica e subclínica, com intensidade variável da resposta em função do tipo e virulência do agente etiológico envolvido no processo infeccioso (Fthenakis \& Jones 1990,
Fthenakis et al. 1991, De La Fuente et al. 1993, Ariznabarreta et al. 2002, Gonzalo et al. 2002, Suarez et al. 2002, Winter et al. 2003).

Em nosso meio são escassas as informações sobre as manifestações clínicas e as alterações quantitativas dos principais componentes do leite em ovelhas com mastite. Portanto, o presente estudo teve por objetivo avaliar a influência da mastite induzida experimentalmente por Staphylococcus aureus sobre as manifestações clínicas e as principais características físico-químicas e celulares do leite.

\section{MATERIAL E MÉTODOS}

O trabalho foi realizado no aprisco de experimentação para pequenos ruminantes da Clínica de Bovinos, Campus Garanhuns da Universidade Federal Rural de Pernambuco (UFRPE).

Foram utilizadas 10 ovelhas prímiparas, recém-paridas de aproximadamente dois anos de idade, Santa Inês, que eram mantidas em aprisco. A dieta foi constituída de feno de tifton (Cynodom sp), capim-elefante (Pennisetum purpureum), concentrado (aprox. 200g/ animal/dia), sal mineral e água ad libitum. Os animais, previamente ao experimento, foram submetidos ao exame clínico de acordo com as recomendações descritas por Radostits et al. (2000), a fim de verificar a higidez dos mesmos.

Foi utilizada uma cepa de campo de Staphylococcus aureus, oriunda de um caso de mastite clínica em ovelha, que foi previamente testada frente a diferentes antimicrobianos. A cepa foi mantida criopreservada em caldo infuso cérebro-coração (BHI), associado ao glicerol. Previamente foi realizado um subcultivo da amostra em ágar sangue (carneiro) a 5\%. No dia anterior à inoculação, as colônias foram repicadas em caldo de enriquecimento $\mathrm{BHI}$ e incubadas a $37^{\circ} \mathrm{C}$ por 24 horas, com posterior passagem e diluição decimais $\left(10^{-1}\right.$ a $\left.10^{-5}\right)$ para PBS, pH 7,2, empregando-se $1,0 \times 10^{4}$ unidades formadoras de colônias (ufc) no inóculo.

\section{Momentos experimentais}

Previamente à inoculação foram estabelecidas as informações clínicas, as características físico-químicas e celulares do leite, mediante a realização de duas colheitas diárias (manhã e tarde), durante três dias, cuja finalidade era estabelecer um valor médio para cada uma das variáveis estudadas, determinando-se com isso os valores iniciais (momento inicial $=0 \mathrm{~h}$ ). Este procedimento foi realizado a partir do $15^{\circ}$ dia após o parto. Os borregos foram removidos de suas mães após mamarem o colostro. Estas passaram a ser ordenhadas manualmente, seguindo normas de controle higiênico-sanitário nas ordenhas.

Após obter os índices das variáveis do momento inicial, na manhã seguinte, a glândula mamária direita do animal em estudo foi infectada experimentalmente com a cepa de $S$. aureus por meio de uma sonda uretral $n^{\circ} 4$ acoplada a uma seringa plástica estéril. A anti-sepsia em ambos os tetos foi realizada com álcool iodado. Após a inoculação na parte proximal da cisterna foi realizada massagem com movimentos ascendentes para o inóculo se distribuir na glândula mamária. A partir deste instante os animais foram acompanhados diariamente, mediante avaliação clínica e análise do leite nas duas ordenhas diárias.

A mastite foi reconhecida no momento em que foram evidenciadas as alterações clínicas da glândula mamária e as características do leite, por meio dos achados laboratoriais, como a contagem de células somáticas iguais ou superiores a $1,0 \times 10^{6}$ de células $/ \mathrm{ml}$ de leite (Green 1984, Mackie \& Rodgers 1986), e exame bacteriológico positivo com resultado de 5 ou mais $\mathrm{ufc} / \mathrm{ml}$ de leite do $S$. aureus 
(Postle et al. 1978). Dessa forma, os momentos foram estabelecidos da seguinte maneira: momento inicial $(0 \mathrm{~h}), 12,24,36,48,60,72,84$, $96,108,120,132,168,180,288$ e 336 horas pós-infecção.

\section{Tratamento}

O tratamento foi efetuado a partir das 36 horas PI, após a ordenha da tarde, por meio de três aplicações com intervalos de $24 \mathrm{~h}$, administrando o antimicrobiano intramamário (Gentocin Mastite 250mg) e sistêmico (Gentocin Solução Injetável), previamente testado in vitro, associado à aplicação do flunixin meglumine (Banamine), todos produtos do Laboratório Schering Plough Coopers.

\section{Exames laboratoriais}

Células somáticas do leite. As amostras lácteas das glândulas mamárias foram avaliadas por meio do California Mastitis Test (CMT) (Schalm \& Noorlander 1957). A contagem direta de células somáticas do leite foi realizada de acordo com o método de Prescott e Breed, modificado pelo Subcomittee on Screening Tests, National Mastitis Council (1968). O corante utilizado foi o Panótico Rápido (corante para uso hematológico) e o fator microscópico (FM) foi de 352876,82, com a contagem de cem diferentes campos.

Análise das características físico-químicas do leite. A análise dos componentes físico-químicos do leite como o pH, o teor de gordura foram realizadas seguindo as recomendações do Laboratório Nacional de Referência Animal (1981). A determinação do teor de cloretos foi realizada utilizando-se de espectrofotômetro e um kit comercial (Labtest Diagnóstica Ltda).

Exame bacteriológico. As amostras de leite foram semeadas segundo as recomendações da International Dairy Federation (1981), sendo observadas as características de crescimento da cepa de $S$. aureus inoculado, de acordo com Carter \& Cole Júnior (1990). As placas que não apresentaram crescimento bacteriano foram mantidas incubadas por mais 24 horas antes de serem descartadas.

\section{Análise estatística}

Os valores obtidos foram analisados ao longo dos momentos experimentais, comparando-os entre si e entre os grupos das mamas controle e inoculada, tendo a média como medida de tendência central, empregando-se a análise de variância, segundo Curi (1997). As estatísticas $\mathrm{F}$ calculadas foram consideradas significativas quando $\mathrm{p}<0,05$; calculando-se a diferença mínima significativa (dms) para á $=0,05$. Para efeito de cálculo estatístico só foram analisados os momentos $0 \mathrm{~h}, 12 \mathrm{~h}, 24 \mathrm{~h}$ e $36 \mathrm{~h}$ PI. Utilizou-se o programa de computador Statwinä (SigmaStat) para a análise estatística dos resultados.

\section{RESULTADOS E DISCUSSÃO}

A inoculação intramamária com $1,0 \times 10^{4} \mathrm{ufc} / \mathrm{mL}$ de Staphylo-coccus aureus, induziu um quadro de mastite clínica aguda em todas as ovelhas, observada às $12 \mathrm{~h}$ em uma e às $24 \mathrm{~h}$ PI nas demais glândulas inoculadas. $\mathrm{O}$ agente foi isolado da amostra de leite obtida às $24 \mathrm{~h}$ PI em todas as mamas comprometidas, enquanto nas controles o crescimento foi negativo. Ao exame clínico foram constatados sinais evidentes da mastite clínica, de curso superagudo, inclusive com um quadro sistêmico como apatia, febre, congestão da mucosa ocular, taquicardia, taquipnéia, anorexia, hipomotilidade a atonia ruminal, ausência da ruminação, fezes diarréicas, claudicação do membro correspondente á glândula inoculada, perda de peso, inclusive a morte de um animal.

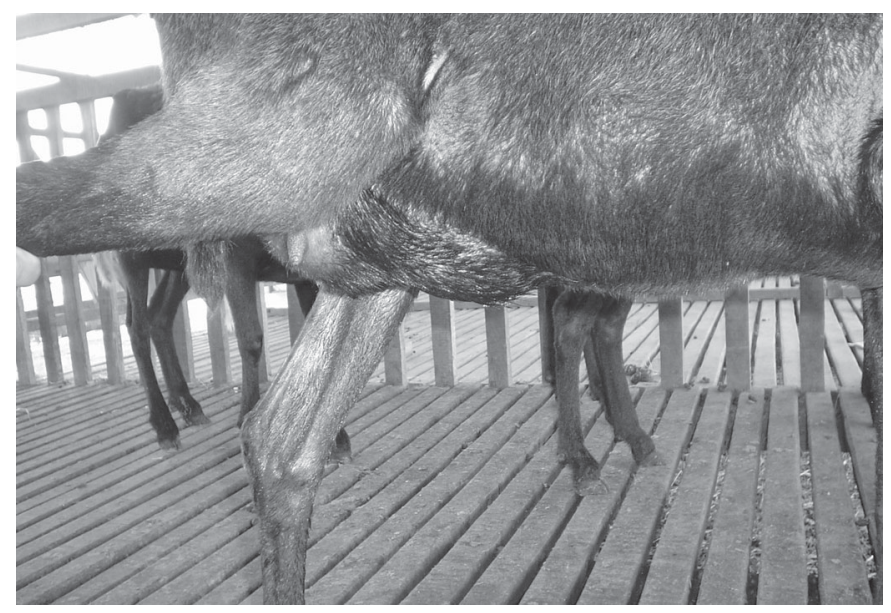

Fig.1. Edema observado 24 horas após a inoculação de cultivo de Staphylococcus aureus na mama de ovelha.

Ao exame da glândula mamária observou-se assimetria da mama inoculada, a partir das $24 \mathrm{~h} \mathrm{PI}$, com edema que evoluiu nos dias seguintes estendendo-se em algumas ovelhas até a região xifóide; a sensibilidade e a temperatura estavam elevadas à palpação e diminuiu ao longo dos dias de evolução da doença (Fig.1). A coloração da pele era inicialmente avermelhada tornando-se depois cianótica e fria ao toque, exsudando em alguns animais uma secreção soro-sanguinolenta; o linfonodo mamário correspondente estava hipertrofiado. Todavia, a partir do tratamento foi verificado em alguns animais o retorno gradativo à normalidade dos indicadores clínicos como apetite, comportamento, temperatura, freqüências cardíaca e respiratória, coloração da mucosa, motilidade ruminal e a ruminação, que foi mais bem observado no último momento de avaliação.

A secreção da glândula mamária inoculada inicialmente apresentou-se alterada com a presença de grumos, e com a gravidade da doença o aspecto tornou-se de leite-sanguinolento a soro-sanguinolento (Fig.2). Além da redução drástica do volume de leite produzido, foi observada a obstrução da cisterna, dificultando a ordenha. Estas manifestações clínicas foram observadas a partir das $12 \mathrm{~h}$ PI. Entretanto, com a evolução

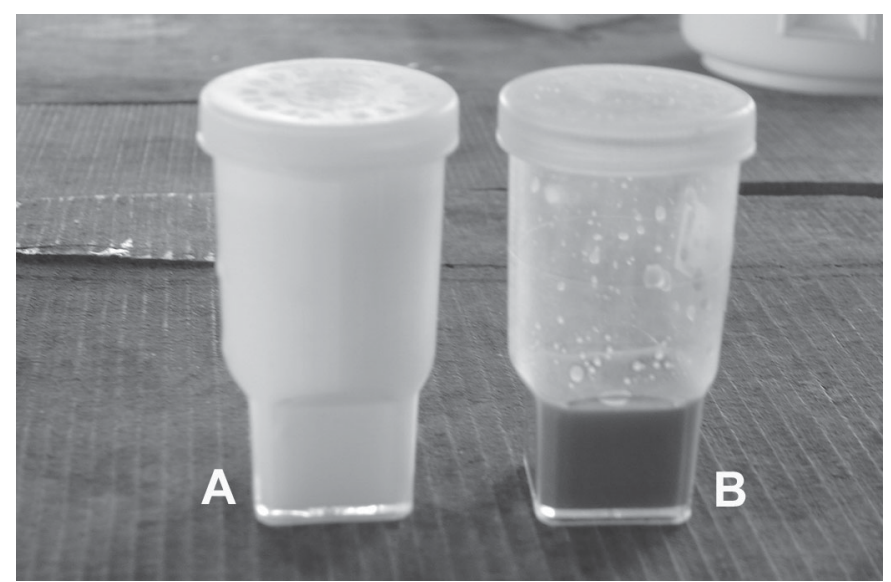

Fig.2. Secreção láctea normal de ovelha (A) e soro-sanguinolenta da mama (B) que recebeu o inóculo de Staphylococccus aureus. 


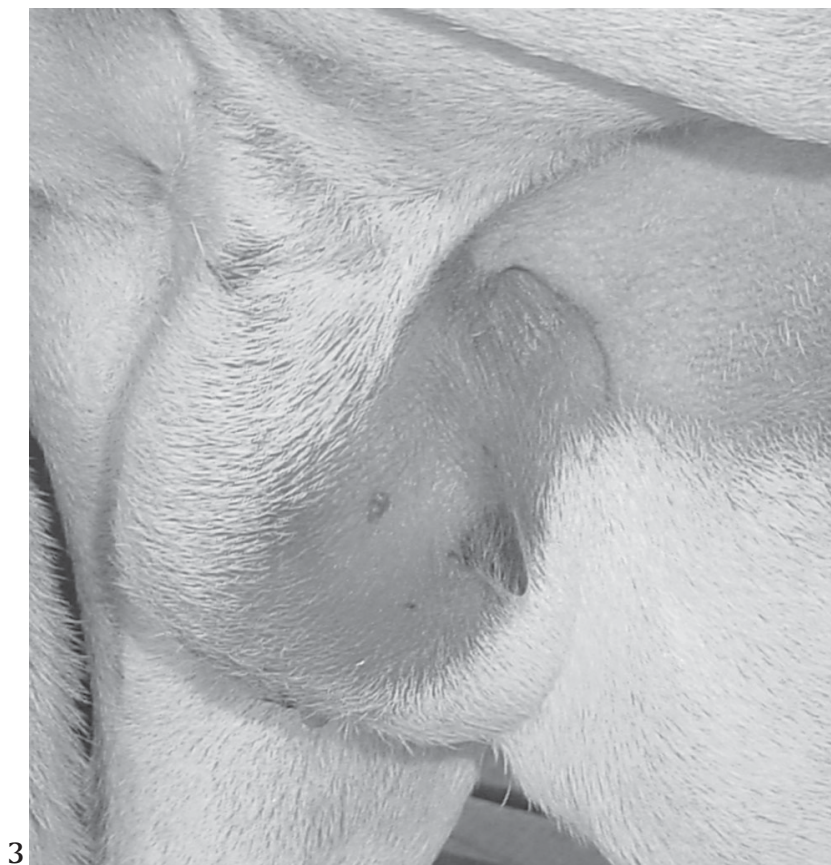

Fig.3. Aspecto de cor cianótica na glândula mamária de ovelha, após 72 horas da inoculação com cultivo de Staphylococcus aureus.

Fig.4. Desprendimento da glândula mamária inoculada e tecidos vizinhos com gangrena, 30 dias após a inoculação com cultivo de Staphylococcus aureus.

da doença, o quadro clínico da glândula mamária inoculada de nove animais agravou-se, mesmo após o tratamento. Com isso, não houve o restabelecimento funcional de nenhuma delas, apresentando-se cianóticas em toda a extensão do parênquima mamário, seguidas de gangrena e queda do tecido lesado por volta do $30^{\circ}$ dia PI (Fig.3 e 4), inclusive o próximo à mama. Em um animal ocorreu apenas o fibrosamento com a formação de abscessos, que romperam próximo ao $30^{\circ}$ dia $\mathrm{PI}$, comprometendo também a sua função produtiva. Vale ressaltar que uma das ovelhas morreu às $48 \mathrm{~h} \mathrm{PI}$ devido à severidade das manifestações clínicas provocadas pela doença.

Os achados clínicos do presente trabalho são condizentes aos encontrados por Kimberling (1988), Kirk \& Gleen (1996), Vaz (1996), Costa et al. (2001), Ladeira (2001), Menzies \& Ramanoon (2001) e Winter (2001), que relataram também nos casos de mastite clínica em ovelhas a depressão, febre seguida de hipotermia, desidratação, anorexia e claudicação do membro do lado afetado. A doença, de evolução rápida, é seguida da formação de edema, que está usualmente presente na frente do úbere acompanhando a veia mamária. São observados ainda calor e dor, a pele da glândula mamária doente torna-se avermelhada, evoluindo para púrpura e fria ao toque, podendo exsudar uma secreção soro-sanguinolenta. A descoloração muitas vezes estende-se além da mama para a parede do abdômen. A secreção mamária se apresenta com aspecto de soro a avermelhada. A extensão da gangrena é variável e em muitos casos é restrita a uma parte localizada do úbere; todavia, comumente toda glândula, pele e tecido

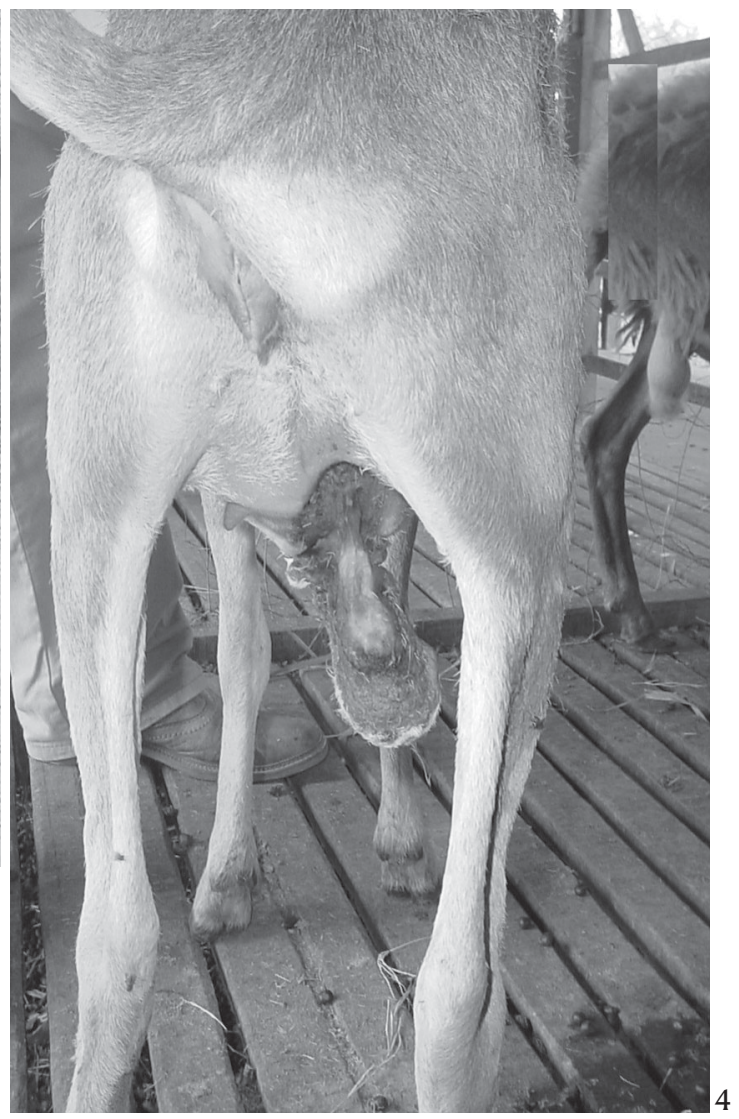

subcutâneo adjacente à veia mamária são comprometidos, inclusive com trombose desta veia. Entretanto, se o animal sobrevive à fase inicial, a glândula e os tecidos vizinhos com a lesão de gangrena tendem a cair após um período de algumas semanas, formando uma ferida que se cura por segunda intenção. Os casos de fatalidade podem alcançar coeficientes de $40 \%$, se a condição clínica não é tratada.

$\mathrm{O}$ agente inoculado provocou uma redução significativa $(\mathrm{P}<0,05)$ no volume de leite produzido pelas ovelhas, afetando tanto as glândulas inoculadas como também as controles. Esta redução foi mais expressiva às 36 horas PI, quando comparado ao momento inicial, alcançando os valores médios de $8,93 \mathrm{ml}( \pm 6,25)$ e $14,6 \mathrm{ml}( \pm 9,35)$ por ordenha, respectivamente. Durante a evolução da doença não foram evidenciadas diferenças significativas $(\mathrm{P}>0,05)$ entre os grupos; entretanto, houve uma tendência de diferença entre os mesmos às 36 horas PI, ocasião em que as glândulas inoculadas apresentaram valores inferiores quando comparados aos seus controles (Fig.5).

Após o tratamento dos animais foi verificado que o retorno da produção nas glândulas controles ocorreu apenas em alguns animais quando comparado ao momento inicial. Com relação às glândulas inoculadas não houve recuperação de nenhuma delas e, conseqüentemente, a produção foi totalmente comprometida. No caso em estudo a cepa mostrou-se bastante virulenta, comprometendo todo o parênquima funcional da glândula inoculada. Estes resultados assemelhamse com os de Kitchen (1981), Fthenakis \& Jones (1990), Al- 
Majali \& Jawabreh (2003) e Leitner et al (2003), quando citam que a mastite provoca redução na produção de leite, e que os efeitos patológicos sobre o tecido do úbere variam com o tipo de organismo que esteja invadindo, no caso do $S$. aureus é bem conhecido que toxinas específicas produzidas são responsáveis por lesões graves na mama, como a a-toxina que produz necrose nos alvéolos.

A inoculação provocou uma elevação significativa $(\mathrm{P}<0,05)$ às $36 \mathrm{~h} \mathrm{PI}$ nos valores do $\mathrm{pH}$ do leite na mama inoculada quando comparado com o momento inicial, alcançando o valor de $6,9( \pm 0,30)$. Diferenças estatísticas $(P>0,05)$ não foram encontradas entre as mamas controles e inoculadas ao longo dos momentos (Fig.5). Embora nesta fase foi verificado que os valores para $\mathrm{o} \mathrm{pH}$ no leite nas glândulas controle apresentaram uma elevação nos seus valores quando comparado ao momento inicial. Com relação ao quarto inoculado, neste período não foi possível mensurar esta variável, uma vez que ocorreu um grave comprometimento da glândula provocada pela intensidade da doença, que acarretou uma produção insuficiente de leite.

Estes resultados assemelham-se com os relatos de Schalm (1977), Schultz (1977) e Korhonen \& Kaartinen (1995), que justificam a elevação do $\mathrm{pH}$ no leite durante os casos de mastite devido à alteração na permeabilidade capilar, que é provocada pela intensa reação inflamatória; como consequiência há a passagem de certos íons como o cloreto de sódio e bicarbonato de sódio causando uma variação no pH e levando-o próximo à neutralidade. Tal fato também foi citado por Kitchen (1981), que associou o aumento da passagem destes íons do sangue para o leite em vacas com mastite clínica com o aumento da permeabilidade capilar.

Com a instalação da infecção foi constatado que ocorreu uma redução significativa $(\mathrm{P}<0.05)$ de $35 \%$ no teor de gordura no leite da glândula inoculada, com maior intensidade às 36 horas PI. Com a evolução da doença, diferenças entre as glândulas controles foram observadas as 24 e 36 horas PI (Fig.6). Após este período, mesmo com o tratamento realizado, não ocorreu o restabelecimento funcional das glândulas inoculadas em todas as ovelhas estudadas, comprometendo desta forma a produção deste componente do leite.

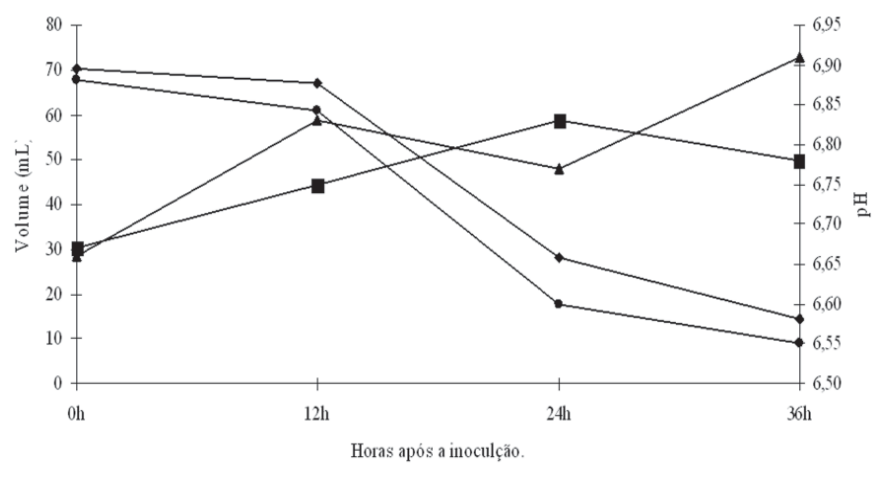

$\rightarrow$ Volume (mL) Inoculada $\rightarrow-$ Volume (mL) Controle $\rightarrow$ pH Leite Inoculada $\rightarrow$ - pH Leite Controle

Fig.5. Valores médios do volume e do pH do leite das glândulas mamárias inoculadas e controle na mastite experimental por Staphylococcus aureus em ovelhas.

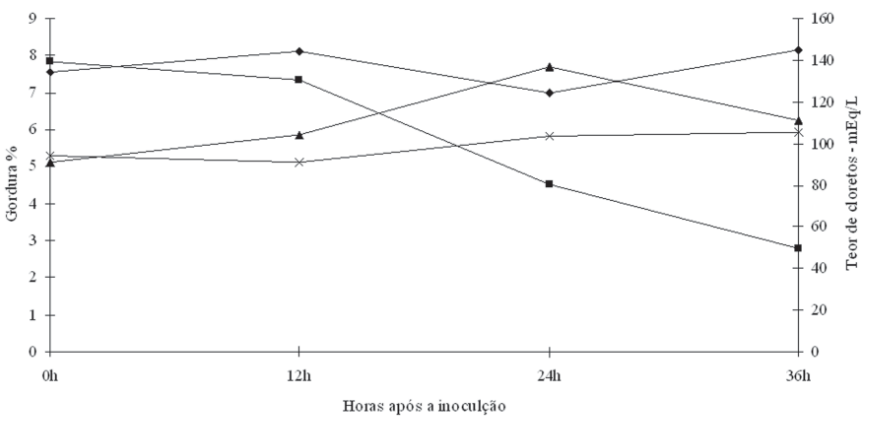

Fig.6. Valores médios da gordura e do teor de cloreto do leite das glândulas mamárias inoculadas e controle na mastite experimental por Staphylococcus aureus em ovelhas.

Kitchen (1981) afirma que como resultado da infecção do úbere a porcentagem de gordura do leite reduz em pequena quantidade. Já Leitner et al. (2003), em estudos sobre a mastite subclínica em ovelhas, avaliaram que a percentagem de gordura era mais baixa em glândulas não infectadas do que nas infectadas, atribuindo esta alteração à redução no volume de leite. No entanto, Burriel (1997) relatou que a infecção intramamária em ovelhas com Staphylococcus coagulase-negativo causou aumento do teor de gordura e proteína e redução da caseína. Segundo Schultz (1977), as modificações no teor da gordura nas mastites são diversas e podem, às vezes, ser uma exceção nas alterações que acontecem na composição do leite; em situações em que a produção de leite é reduzida mais que a síntese de gordura, a percentagem desta aumenta. Assim, com os resultados do presente estudo, a redução no teor de gordura no leite pode ser explicada pela reduzida síntese deste componente devido à injúria nas células secretoras.

Durante a infecção intramamária foi verificado um aumento significativo $(\mathrm{P}<0,05)$ do teor de cloreto no leite das glândulas inoculadas às 24 horas PI, quando comparado ao momento inicial e as glândulas controles, alcançando os valores médios de 136,7mEq/L e 103,45mEq/L, respectivamente (Fig.6). Quanto à glândula inoculada, a supressão da produção de leite provocada pela doença impediu que esta variável fosse mensurada nos períodos seguintes às 36 horas $\mathrm{PI}$.

As alterações ocorridas foram relatadas por Schalm (1977), Pÿoralla \& Mattila (1987) e Afonso \& Vianni (1995), que atribuiram as modificações na composição do leite durante a mastite como reflexo à intensidade das alterações inflamatórias que ocorrem no úbere, e que a primeira mudança detectável é o surgimento de proteínas do plasma no leite como consequiência do aumento da permeabilidade entre o sangue e o compartimento do úbere que sintetizam o leite; eletrólitos, tal como sódio e cloreto, também penetram no leite elevando as suas concentrações.

Após a inoculação, foi constatada uma elevação significativa $(\mathrm{P}<0,05)$ na CCS do leite das glândulas inoculadas a partir das 12 horas PI. Avaliadas pelo CMT as reações variaram de discretas $( \pm)$ a moderadas $(++)$ em 5 ovelhas; sendo a contagem mais expressiva entre as 24 e 36 horas PI quando comparado ao momento anterior a inoculação e à glândula 


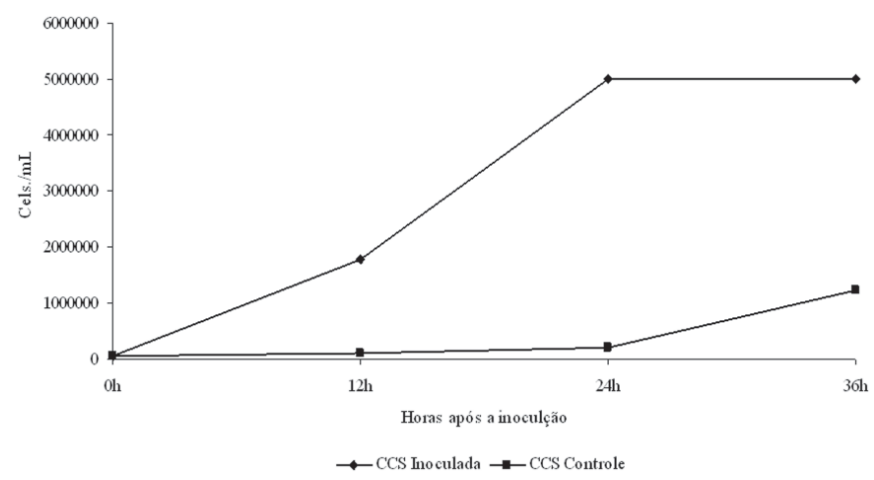

Fig.7. Valores médios da contagem de células somáticas (CCS) no leite das glândulas mamárias inoculadas e controle na mastite experimental por Staphylococcus aureus em ovelhas.

controle, onde os valores ficaram acima de $5,0 \times 10^{6}$ céls. $/ \mathrm{mL}$ (Fig.7). A partir das 36 horas PI, mesmo após o tratamento dos animais e com a evolução da doença, foi observada também uma elevação dos valores da CCS na glândula controle quando comparado ao momento inicial. Tal fato se justifica pela redução no volume de leite que ocorreu neste período. Quanto à glândula inoculada, nesta etapa não foi possível mensurar esta variável devido à supressão da produção de leite causada pela doença.

Nos presente trabalho os valores expressivos da celularidade estão relacionados à severidade do processo clínico da doença. Estas observações foram relatadas também por Persson et al. (1997), que induziram experimentalmente mastite em ovelhas utilizando $S$. aureus e observaram um significativo acúmulo de leucócitos no leite a partir de 8 horas $\mathrm{PI}$, com pico após 24 horas, em que grande quantidade do agente foi recuperada do leite durante todo o experimento. El-Masannat et al (1991), relataram que nos casos de mastite induzida experimentalmente por Pasteurella haemolytica o aumento na contagem de células somáticas no leite ocorreu aproximadamente 12 horas após a inoculação. Entretanto, eles citam que geralmente após 24 horas as amostragens eram insuficientes para a contagem de células, o que no presente trabalho ocorreu somente após as 36 horas PI. Tal fato justifica-se pela intensidade como a doença se manifestou. Albenzio et al (2002), afirmaram que o aumento na contagem de células somáticas é um índicador confiável da ocorrência da mastite em ovelhas, uma vez que a infiltração leucocitária nos alvéolos constitui um dos mecanismos de defesa dos animais contra a infecção.

A inoculação intramamária de $S$. aureus induziu uma mastite de evolução aguda em todas as ovelhas e o tratamento efetivado foi possibilitou a sobrevivência do animal, porém não reverteu o dano causado às glândulas inoculadas. Isto posto, a iniciativa terapêutica nos casos agudos de mastite clínica em ovelhas por $S$. aureus tem que ser realizada de forma precoce devido aos riscos de vida para o animal.

Agradecimentos.- À Fundação de Amparo à Ciência e Tecnologia do Estado de Pernambuco (FACEPE/MCT-CNPq, Programa primeiros projetos de apoio à infra-estrutura de CT\&I para jovens pesquisadores).

\section{REFERÊNCIAS}

Afonso J.A.B. \& Vianni M.C.E. 1995. Variação do teor de cloretos e acidez Dornic no leite de vacas com mastite induzida experimentalmente. Revta Univ. Rural, Sér. Ciênc.Vida., Seropédica, 17:1-6.

Albenzio A., Taibi L., Muscio A. \& Sevi A. 2002. Prevalence and etiology of subclinical mastitis in intensively managed flocks and related changes in the yield and quality of ewe milk. Small Rum. Res. 43:219-226.

Al-Majali A.M. \& Jawabreh S. 2003. Period prevalence and etiology of subclinical mastitis in Awassi sheep in southern Jordan. Small Rum. Res. 47:243-248.

Ariznabarreta A., Gonzalo C. \& Primitivo F. 2002. Microbiological quality and somatic cell count of ewe milk with special reference to Staphylococci. J. Dairy Sci. 85:1370-1375.

Batavani R.A., Mortaz E., Falahian K. \& Dawoodi M.A. 2003. Study on frequency, etiology and some enzymatic activities of subclinical ovine mastitis in Urmia, Iran. Small Rum. Res. 50:45-50.

Burriel A.R. 1997. Dynamics of intramammary infection in the sheep caused by coagulase-negative Staphylococci and its influence on udder tissue and milk composition. Vet. Rec. 140:419-423.

Carter E.R. \& Cole Junior J.R. 1990. Diagnostic Procedures in Veterinary Bacteriology and Micology. $5^{\text {th }}$ ed. Academic Press, New York. 620p.

Costa N.A., Mendonça C.L., Afonso J.A.B., Souza M.I., Calado A.L., Pires J.R., Coutinho L.T., Simão L.C.V. \& Cavalcante A.E.L. 2001. Ocorrência de mastite em ovelhas atendidas na Clínica de Bovinos. XXVIII Congr. Bras. Med. Vet., Salvador, BA, p.123. (Resumo)

Curi P.R. 1997. Metodologia e Análise da Pesquisa em Ciências Biológicas. Tipomic, Botucatu. 263p.

De La Fuente R., Quiteria J.A.R.S., Domingo M. \& Suarez G. 1993. Experimental intramammary infection of ewes with Staphylococcus aureus subsp. anaerobius. Res. Vet. Sci. 54:221-226.

El-Masannat E.T.S., Jones J.E.T. \& Scott M.J. 1991. The experimental production of mastitis in sheep by intramammary inoculation of Pasteurella haemolytica. J. Comp. Path. 105:455-465.

Fernandes J.C.T. \& Cardoso M.R.I. 1985. Mamite ovina causada por Staphylococcus aureus. Primeira observação no Brasil. Arq. Fac. Vet., UFRGS, Porto Alegre, 13:71-74.

Fthenakis G.C. \& Jones J.E. 1990. The effect of inoculation of coagulasenegative Staphylococci into the ovine mammary gland. J. Comp. Pathol. 102:211-219.

Fthenakis G.C., El-Masannat E.T.S., Booth J.M. \& Jones E.T. 1991. Somatic cell counts of ewes' milk. Brit. Vet. J. 147:575-581.

Gonzalo C., Ariznabarreta A., Carriedo J.A. \& San Primitivo F. 2002. Mammary pathogens and their relationship to somatic cell count and milk yield losses in dairy ewes. J. Dairy Sci. 85:1460-1467.

Green T.J. 1984. Use of somatic cell counts for detection of subclinical mastitis in ewes. Vet. Rec. 114:43.

International Dairy Federation 1981. Bulletin Laboratory Methods for Use in Mastitis Work. Document 132, Brussels. 27p.

Kimberling C.V. 1988. Jensen and swift's diseases of sheep. $3^{\text {rd }}$ ed. Lea and Febiger, Philadelphia. 394p.

Kirk J.H. \& Glenn J.S. 1996. Mastitis in ewes: The compendium for continuous education for veterinarian practice. Food Anim. 18:582-591.

Kitchen B.J. 1981. Review of the progress of dairy science: Bovine mastitis, milk compositional changes and related diagnostic tests. J. Dairy Res. 48:167-188.

Korhonen H. \& Kaartinen L. 1995. Changes in the composition of milk induced by mastitis, p.76-82. In: Sandholm M., Buzalski T.H., Kaartinen L. \& Pyörälä S. (ed.), The Bovine Udder and Mastitis. Gummerus Kirjapaino, Helsinki.

Ladeira S.R.L. 2001. Mastite ovina, p.312-316. In: Riet-Correa F., Schild A.L., Méndez M.D.C. \& Lemos R.A.A. (ed.), Doenças de Ruminantes e Eqüinos. Vol.1. 2 ${ }^{a}$ ed. Editora Varela e Livraria Ltda, São Paulo.

Lanara - Laboratório Nacional de Referência Animal 1981. Métodos Analíticos Oficiais para Controle de Produtos de Origem Animal e seus Ingredien- 
tes. II. Métodos físicos e químicos. Secretaria Nacional de Defesa Agropecuária, Ministério da Agricultura, Brasília. 201p.

Leitner G., Chaffer M., Caraso Y., Ezra E., Kababea D., Winkler M., Glickman A. \& Saran A. 2003. Udder infection and milk somatic cell count, NAGase activity and milk composition - fat, protein and lactose- in Israeli-Assaf and Awassi sheep. Small Rum. Res. 49:157-164.

Mackie D.P. \& Rodgers S.P. 1986. Mastitis and cell content in milk from Scottish blackface ewes. Vet. Rec. 118:20-21.

Mendonça C.L., Afonso J.A.B., Costa N.A. 2005. Mastite em ovelhas. Vet. Zootec. CRMV-PE, Recife, 25:7.

Menzies P.I. \& Ramanoon S.Z. 2001. Mastitis of sheep and goats. Vet. Clin. North. Am. Food Anim. Pract. 17:333-358.

Persson W.K., Colditz I.G. \& Seow H.F. 1997. Accumulation of leucocytes and cytokines in the lactating ovine udder during mastitis due Staphylococcus aureus and Escherichia coli. Res. Vet. Sci. 62:63-66.

Postle D.S., Roguinski M. \& Poutrel B. 1978. Induced staphylococcal infections in the bovine mammary gland. Am. J. Vet. Res. 39:29-35.

Pyörälä S. \& Mattila T. 1987. Inflammatory changes during experimental bovine mastitis induced by Staphylococcus aureus, Streptococcus dysgalactiae and Streptococcus uberis. J. Vet. Med. A 34:574-581.

Radostits O.M., Gay C.C., Blood D.C. \& Hinchcliff K.W. 2000. Veterinary Medicine. 9th ed. Baillière Tindall, London. 1877p.

Schalm O.W. \& Noorlander D.O. 1957. Experiments and observations leading to development of the California Mastitis Test. J. Am. Vet. Med. Assoc. 130:199-204.
Schalm O.W. 1977. Pathologic changes in the milk and udder of cows with mastitis. J. Am. Vet. Med. Assoc. 170:1137-1140.

Schultz L.H. 1977. Somatic cells in milk: physiological aspects and relationship to amount and composition of milk. J. Food Protec. 40:125-131.

Scott M.J. \& Jones J.E.T. 1998. The carriage of Pasteurella haemolytica in sheep and its transfer between ewes and lambs in relation to mastitis. J. Comp. Path. 118:359-363.

Suarez V.H., Busetti M.R., Miranda A.O., Calvinho L.F., Bedotti D.O. \& Canavesio V.R. 2002. Effect of infectious status and parity on somatic cell count and California mastitis test in panpinta dairy ewes. J. Vet. Med. B Infect. Dis. Vet. Publ. Hlth, 49:230-234.

Subcomittee on Screening Tests - National Mastitis Council. 1968. Direct microscopic somatic cell count in milk. J. Milk Food Techn. 31:350-354.

Vaz A.K. 1996. Mastite em ovinos. Hora Vet., Porto Alegre, 16:75-77.

Watkins G.B., Burriel A.R. \& Jones J.E. 1991. A field investigation of subclinical mastitis in sheep in southern England. Brit. Vet. J. 147:413-420.

Watson D.J. \& Buswell J.F. 1984. Modern aspects of sheep mastitis. Brit. Vet. J. 140:529-534.

Williams B.M. 1966. Levantamento das causas de mortes de cordeiros no Rio Grande do Sul. Arq. IPVDF, Porto Alegre, 3:23-26.

Winter A. 2001. Mastitis in ewes. In Practice 23:160-163.

Winter, P., Schilcher F., Fuchs K. \& Colditz I.G. 2003. Dynamics of experimentally induced Staphylococcus epidermidis mastitis in East Friesean milk ewes. J. Dairy Res. 70:157-164. 